\title{
Nanduty
}

ISSN:2317-8590

\section{ARTEFATOS, HISTÓRIA E CULTURA: URNAS MORTUÁRIAS E DINÂMICAS DOS CONTATOS}

\author{
Marcel Mano (UFU - marcelmano@ufu.br) \\ Tayná Bonfim Mazzei Mazza (UFU/CNPq - tayna_mazza@hotmail.com)
}

\begin{abstract}
RESUMO
O ARTIGO CONJUGA INTERESSES DA ANTROPOLOGIA, DA ARQUEOLOGIA E DA HISTÓRIA AO DISCUTIR REGISTROS ARQUEOLÓGICOS DE URNAS MORTUÁRIAS NA REGIÃO DO TRIÂNGULO MINEIRO, NORTE DE SÃO PAULO E SUL DE GOIÁS DURANTE O PERÍODO COLONIAL. COM BASE NUMA SÉRIE DE MATERIAIS ARQUEOLÓGICOS, DOCUMENTAIS E BIBLIOGRÁFICOS DISPONÍVEIS BUSCA-SE COMPREENDER ESSES REGISTROS A PARTIR DOS CONTEXTOS DE CONTATOS INTERTRIBAIS E INTERÉTNICOS QUE SE DESENVOLVIAM NOS SÉCULOS XVIII E XIX, CONFORME SE DEPREENDE DA DOCUMENTAÇÃO HISTÓRICA. A PARTIR DO CONTEXTO DOS CONTATOS ESPERA-SE PROBLEMATIZAR A PRESENÇA DAS URNAS MORTUÁRIAS NESSA REGIÃO NO PERÍODO HISTÓRICO, SOBRETUDO EM RELAÇÃO AOS CONTEXTOS FOSSILIZADOS DAS CLASSIFICAÇÕES E DAS TRADIÇÕES, E APONTAR PARA OS PROCESSOS DINÂMICOS DE REDES E TROCAS ENTRE DIFERENTES ALTERIDADES, PARA OS QUAIS OS REGISTROS PARECEM APONTAR.
\end{abstract}

PALAVRAS-CHAVE: HISTÓRIA INDÍGENA; JÊ MERIDIONAIS; CULTURA.

\section{ABSTRACT}

THE ARTICLE CONJUGATES INTERESTS OF ANTHROPOLOGY, ARCHEOLOGY AND HISTORY WHEN DISCUSSING ARCHAEOLOGICAL RECORDS OF MORTUARY URNS IN THE REGION OF TRIÂNGULO MINEIRO, NORTH OF SÃO PAULO AND SOUTH OF GOIÁS DURING THE COLONIAL PERIOD. BASED ON A SERIES OF AVAILABLE ARCHAEOLOGICAL, DOCUMENTARY AND BIBLIOGRAPHIC MATERIALS, IT IS INTENDED TO UNDERSTAND THESE RECORDS FROM THE CONTEXTS OF INTERTRIBAL AND INTERETHNIC CONTACTS DEVELOPED IN THE 18TH AND 19TH CENTURY, AS CAN BE SEEN FROM THE HISTORICAL DOCUMENTATION. FROM THE CONTEXT OF THE CONTACTS IT IS EXPECTED TO PROBLEMATIZE THE PRESENCE OF THE MORTUARY URNS IN THAT REGION IN THE HISTORICAL PERIOD, ESPECIALLY IN RELATION TO THE FOSSILIZED CONTEXTS OF CLASSIFICATIONS AND TRADITIONS, AND TO POINT FOR THE DYNAMIC PROCESSES OF NETWORKS AND CHANGES BETWEEN DIFFERENT ALTERITIES, FOR WHICH THE RECORDS SEEM TO POINT.

KEY WORDS: INDIGENOUS HISTORY; SOUTHERN JÊ; CULTURE.

INTRODUÇÃO 
$\mathrm{O}$ artigo conjuga interesses da Antropologia, da Arqueologia e da História ao discutir registros arqueológicos de urnas mortuárias na região do Triângulo Mineiro, norte de São Paulo e sul de Goiás durante o período colonial. Com base numa série de materiais arqueológicos, documentais e bibliográficos disponíveis estudam-se esses registros em relação aos contextos de contatos intertribais e interétnicos ${ }^{1}$ que se desenvolviam nesse período e região. A intenção é mostrar que esses registros arqueológicos espelham os processos contínuos de construção e reconstrução de identidades quando do encontro entre diferentes alteridades. Nessa história os contatos, encontros, fluxos, itinerários e interstícios são pensados a partir do rizoma, porque "qualquer ponto pode ser conectado a qualquer outro e deve sê-lo." (DELEUZE; GUATTARI: 2011:14). Isso quer dizer que os encontros entre diferentes alteridades mutuamente afetam e conectam a todas, traçando rotas não lineares, semelhantes então à imagem do rizoma. A utilidade desse modelo reside em compreendermos a etnologia, a história indígena e as tradições arqueológicas não como unidades fechadas em si, mas como sistemas abertos, compostos de dimensões, ramificações, linhas e trajetos de diversas semióticas.

O ponto de partida dessa reflexão encontra-se nos relatos do memorialista Hildebrando Pontes, em seu trabalho História de Uberaba e a civilização no Brasil central, datado de 1930. Pontes descreve o achado de urnas mortuárias em diferentes oportunidades nas proximidades da cidade de Uberaba, no coração do Triângulo Mineiro. Dentre as urnas descritas, duas delas despertam a curiosidade. Uma dessas urnas foi encontrada no barranco direito do Rio Branco, um afluente do rio Grande, quando da construção da chamada Ponte do Surubi, demolida ainda na década de sessenta quando da construção da Usina Hidrelétrica dos Peixotos - represa dos Peixotos - na cidade de Delfinópolis/MG. Descrevendo a urna, Pontes (1930:13) afirma que "Naquelas imediações, em 1903, foi descoberta uma igaçava ou igaçaba, na qual encontraram, de mistura com ossos, uma bela cruz de ouro, com letras.”.

A segunda urna descrita foi encontrada em abril de 1894, no Capão do Mico, à vista do arraial da Conceição de Araxá, hoje cidade de Araxá/MG. Segundo Pontes, esta segunda urna:

[...] tinha dimensões muito maiores, envolvido em couro solidamente costurado. [...] Era o cadáver de um índio velho, peito largo, rosto levemente triangular, maçãs do

\footnotetext{
${ }^{1}$ Embora sem entrar na pertinência de cada um desses conceitos, o termo contato intertribal será aqui utilizado quando a referência for o contato de grupos indígenas entre si; e interétnico quando a referência for o contato entre grupos indígenas e não indígenas.
} 
rosto saliente e quase imberbe. [...] Na cintura, uma tanga de penas vistosas e nos artelhos enfeites de penas de uma espécie de chocalho, que produzem sons agudos e ásperos. Dentro havia, além de um arco e trinta flechas, uma aljava de couro de cutia, uma rede e duas cuias cobertas de bordados extravagantes[...]. No fundo do vaso, duas manchas, que o autor acha, sem dúvida, sejam provenientes da comida que se derramou nas cuias, quando se deu o enterramento" [...]. Retirando o invólucro, uma verdadeira maravilha se deparou a todas as vistas pela profusão de desenhos toscos, em que o vermelho e o amarelo gritam, num colorido quente e belíssimo, colorindo a talha toda. (PONTES:1930:14)

Tendo em vista as descrições, de imediato dois elementos chamam a atenção, quais sejam:

(I) A existência de uma cruz de ouro com letras junto aos ossos dentro de uma urna mortuária; e

(II) A existência de ampla decoração na segunda urna.

No primeiro caso, é evidente que o artefato cristão em urna indígena evidência como as redes de contato transportam elementos materiais e representações simbólicas, pois nitidamente estão aí associados dois universos ritualísticos funerários inicialmente diferentes. No segundo caso - o da urna policrômica - sabe-se que, tradicionalmente, as tais urnas mortuárias, cerâmicas de decoração pintada ou corrugada, e ligadas a enterramentos primários, foram associadas aos povos indígenas da Tradição Tupiguarani. No entanto, estudos arqueológicos (ALVES:2003; FAGUNDES:2015) em diferentes regiões do Triângulo Mineiro, identificam a arqueologia dessa área como de Tradição Aratu-Sapucaí; assim como estudos de história indígena (MANO:2015), indicam que essa região foi ocupada por diferentes grupos da família linguística Jê do Tronco Macro-Jê, conhecidos na documentação do XVIII pelo termo genérico "Cayapó". Neste caso, como no primeiro, somos levamos às redes e fluxos de contatos para pensar a presença de urnas mortuárias com características da Tradição Tupiguarani, no passado e no presente, em regiões de ocupação histórica Jê.

No exercício aqui proposto não se trata de dar respostas a cada uma dessas inquietações, mas de ter como fronte o desafio de construir quadros explicativos mais abrangentes a respeito das ocupações indígenas na presente região. Talvez eles possam ajudar a desvendar ou dar luz aos contextos e características híbridas dessas urnas. Embora não se queira obviamente propor uma relação direta entre os achados arqueológicos e os contextos históricos e grupos citados nas fontes documentais, acredita-se, porém, que uma das portas para a compreensão desses achados possa ser a dinâmica dos contatos que se deram nessa região no período histórico (colonial), haja vista a presença de um elemento não indígena em 


\section{Nanduty}

uma daquelas urnas. Assim, com base no diálogo entre a Arqueologia, a Etnologia e a História espera-se evidenciar como fluxos, redes e rotas de encontros entre diferentes grupos e alteridades, auxiliam na compreensão da materialidade, da cultura e da história como um processo contínuo de rupturas e continuidades que expressam formas de existir e resistir no mundo.

\section{DO MATERIAL À VIDA}

Sabe-se que a Arqueologia no Brasil ganhou evidência a partir da criação, na década de 1960, do Programa Nacional de Pesquisas Arqueológicas (PRONAPA), que esteve sob a coordenação de Betty Meggers e Clifford Evans. Desde o advento do Programa foram realizadas inúmeras pesquisas de cunho histórico-culturalista cuja intenção era entender fenômenos de origem e dispersão dos grupos humanos pelo território a partir da difusão de determinados elementos materiais. Em seu esforço, esse Programa conectou (talvez de forma precipitada) os registros arqueológicos às identidades étnicas e culturais dos povos que ocuparam determinada região. Muito embora esse Programa tenha sido pioneiro e de grande expressão, as pesquisas empreenderam por anos a tarefa ingrata de adequar, a partir de guias fósseis característicos, sítios e vestígios materiais à constituição de "tradições" e "fases" no Brasil; negligenciando, assim, o aspecto dinâmico dos artefatos e das ocupações humanas.

Dentre as classificações que culminaram nas Tradições Arqueológicas temos a diferenciação entre as Tradições ceramistas Tupiguarani e Aratu-Sapucaí. A primeira tradição foi definida, de acordo com Brochado (1980), pelas técnicas de tratamento da superfície e pela morfologia das vasilhas. São cerâmicas confeccionadas pela técnica do enrolamento em espiral de cordões de barro, e apresentam um cozimento incompleto. As vasilhas podem ser (a) sem decoração, apenas alisadas, (b) apresentar decoração plástica ou (c) pintada, isto é, decoração policrômica (vermelho ou preto sobre engobo branco ou vermelho), corrugada ou escovada. Já a Tradição Aratu-Sapucaí ${ }^{2}$ foi definida por Schimitz

${ }^{2}$ A Tradição Arqueológica Aratú-Sapucaí advém da junção de duas tradições arqueológicas. A tradição Aratú foi formalizada por Valentin Calderón, em 1972, a partir de um estudo pelo PRONAPA, realizado no Distrito de Aratú, na Bahia de Todos os Santos, embora tenha sido encontrada em outras regiões do Nordeste, Centro Oeste e Sudeste do Brasil. A tradição Sapucaí, encontrada em sítios nas regiões de Minas 
et al. (1982:49) pela presença de cerâmica e vasilhas predominantemente simples, produzidas por antiplástico mineral e formas esféricas e ovoides grandes; urnas funerárias piriformes sem decoração - lisas - e vasos geminados.

Apesar de representar avanços, pois é certo de que as tradições arqueológicas são modelos de organização do conhecimento, também é certo que toda classificação é, em certa medida, um modo de desumanização. Por muito tempo a classificação em tradições rejeitou artefatos destoantes do guia fóssil, aqueles que então não se encaixavam nos modelos eram elementos "intrusos", como se convencionou chamar; portanto, relegados a segundo plano. Com base nesse Programa de Pesquisas, e como acima mencionado, os estudos arqueológicos empreendidos na região no Triângulo Mineiro, norte de São Paulo e sul de Goiás passaram a identificar a área como ocupada no passado por povos pertencentes à tradição Aratu-Sapucaí. Em 1980, Márcia Angelina Alves dá início ao "Projeto Quebra Anzol”, realizando pesquisas arqueológicas nas regiões do Alto Paranaíba e Triângulo Mineiro, com prospecções e escavações no vale do Paranaíba. As primeiras pesquisas se desenvolveram no Município de Perdizes, Vale do Quebra Anzol, por ter sido a primeira cidade a coletar vestígios materiais de terrenos, como uma urna funerária, tigelas, potes, raspadores etc. (ALVES:1992:27).

Logo em seguida, com o crescimento desse projeto, vários sítios passaram por processos de prospecção e escavação, como o sítio Silvia Serrote, no Município de Guimarânia; o sítio Rezende, nos vales do Piedade e Paranaíba - divisa com o Estado de Goiás; o sítio Inhazinha, localizado nas jazidas arqueológicas no Município de Perdizes; o sítio Menezes, na Fazenda São Francisco do Borja, também em Perdizes; e o sítio Rodrigues Furtado, na Fazenda Morro da Mesa (ALVES:1992:28). Mais tarde, essa mesma equipe desenvolveu o "Projeto Turvo", localizado no Município de Monte Alto/SP, onde houve a localização e reconhecimento de áreas arqueológicas, sendo

Gerais e São Paulo, chegou a ser considerada inclusive uma fase da tradição Aratú, mas logo depois foi considerada uma tradição independente. O levantamento e constituição desta tradição foi realizada por Ondemar Dias, em 1971, então arqueólogo do PRONAPA. É possível que, por fluxos migratórios, a tradição Aratú tenha chegado até o Centro-Oeste do Brasil, tendo se filiado aos sítios de Goiás e encontrando não apenas a tradição Sapucaí, como outras, como a tradição arqueológica Uru, convencionando-se denominar os sítios de características derivadas dessas tradições de sítios de Tradição Aratú-Sapucaí. 
realizados resgates de sítios arqueológicos, como o de Água Limpa (RASTEIRO:2015:56).

Estes estudos identificaram os sítios arqueológicos como provenientes de comunidades de horticultores-ceramistas, vivendo da caça, da coleta e pesca, tendo sua cultura material voltada a produção de "uma cerâmica lisa, utilitária e funerária", além de viverem em "cabanas ovaladas que formavam verdadeiras aldeias" (ALVES:1992:37). Marcelo Fagundes, em seus estudos a respeito da arqueologia no Triângulo Mineiro também indica características semelhantes a respeito da cultura material da região, sendo a “cerâmica representada por cacos bem alisados em sua maioria, geralmente grossos (...) de vasilhas grandes, provavelmente urnas, até vasilhames bem pequenos." (FAGUNDES: 2015:141). Assim, em sua maioria essas pesquisas apontaram para a tradição AratuSpaucaí, tal como indica João Cabral de Medeiros, a respeito dos sítios Inhazinha e Rodrigues Furtado, no Município de Perdizes, em Minas Gerais,

Diante do exposto, pode-se concluir, que de acordo com os dados corroborados pela literatura e por meio dos estudos técnicos, que as características da cultura material, cerâmica e lítica, dos sítios Inhazinha e Rodrigues Furtado são compatíveis com o que já foi descrito para as populações pretéritas filiadas à tradição Aratu-Sapucaí. (MEDEIROS: 2007:226)

Apesar dessa aparente unanimidade, uma série de relatos e pesquisas indicam, num mesmo sítio arqueológico, a ocorrência de materiais que possuem características diferentes daquelas apontadas pela "tradição de base". Seriam então "sítios arqueológicos complexos" sobre os quais ainda não dispensamos (ou apenas timidamente o fizemos) melhores interpretações. A que aqui é proposta pauta-se no entendimento de que os sítios arqueológicos com artefatos plurais, tais como os achados das urnas descritas por Hildebrando Pontes (1930) no Triângulo Mineiro, podem servir de motivo para pensar não a intrusão, mas a imbricação de elementos de diferentes culturas que circulavam em redes por uma determinada região, cuja expressão, na região em foco, pode ser ilustrada a partir da história dos contatos dos grupos Jê meridionais com seus diferentes outros.

Embora não se possa propor uma associação direta entre as tradições arqueológicas e os grupos historicamente mencionados nas fontes, a escavação e estudo recente nessa mesma região de sítios agricultores ceramistas históricos, datados entre a metade do século XVIII e meados do XIX, também identificados como Aratu-Sapucaí (Magalhães, 2015); assim como a 
mencionada "cruz de ouro com letras" na urna indígena descrita por Pontes (1930) que é indiscutivelmente do período histórico, tornam possível a associação, no mesmo período (colonial) e área, com povos indígenas denominados nas fontes por "Cayapó". O termo "Gentio Cayapó" aparece na documentação histórica em 1723, quando o sertanista Antônio Pires de Campos entra em contato com grupos da bacia do Paranaíba, no atual sul de Goiás. Esse sertanista escreve que "Este gentio é de aldêas, e povoam muita terra por ser mui'a gente, cada aldêa com seu cacique..." (CAMPOS:1976:181). Embora muito encontrado posteriormente em relatos de viajantes, cartas, descrições, essa nomenclatura não nos esclarece de fato quem eram esses povos, já que o termo é de origem exógena, Tupi, e significa "como macaco" (TURNER: 1992).

Ao que parece, "o termo "Cayapó" é um apelativo aplicado por um olhar estrangeiro a uma série de grupos provavelmente associados aos Jê meridionais.” (MANO:2015:520). Por isso, devemos nos atentar que, assim como as denominações arqueológicas das tradições, as denominações que aparecem nos documentos históricos, como "Cayapó", e os modelos etnológicos são generalizações que escondem uma realidade muito mais complexa. Se a realidade é múltipla, os modelos fechados não comportam a realidade, mas parte dela. E como indicam Deleuze e Guattari (2011), não basta dizer o múltiplo, já que "nenhuma habilidade tipográfica, lexical ou mesmo sintática será suficiente para fazê-lo ouvir" (DELEUZE; GUATTARI:2011:21). Nesse sentido, é necessário encontrar o múltiplo nas dimensões de que dispomos, seja a partir dos materiais, dos documentos ou das dinâmicas culturais, e fazê-las serem vistas, ouvidas, pensadas e pronunciadas.

Sítios arqueológicos encontrados e estudados na região demonstram, como mencionado, variabilidade material, vestígios de diferentes tradições em um mesmo local, "fazendo com que pesquisadores (ROBRAHN-GONZÁLES:2000; AFONSO:2005; MANO:2006) começassem inclusive a "iniciar um debate ao tratar o estado de São Paulo como terra de fronteiras”. (RASTEIRO:2015:55). E não apenas em São Paulo, mas na área que abrange o Triângulo Mineiro e o sul de Goiás. A arqueóloga Camila Moraes (2005) em pesquisas realizadas no limite do estado de São Paulo e Minas Gerais, indica que no Sítio Água Vermelha 2, não obstante as cerâmicas encontradas serem de formas duplas e sem decoração, características relacionadas a Tradição Aratú-Sapucaí, 


\section{Nanduty

Segundo Robrahn-Gonzalez et alii (1998), a ocupação do sítio Água Vermelha 2 estaria relacionada ao processo de diversificação cultural ocorrido na região centrooeste, entre os séculos IX e X. Algumas características da cerâmica, como uso do caco moído como antiplástico e as formas compostas, seriam associadas à influência Tupi e o uso de cariapé aos Grupos Uru, indicando cerâmicas de origens variadas como encontradas no Brasil Central. (AFONSO \& MORAES: 2005/2006: 61)

Outro sítio com as mesmas evidências foi o descrito por Renan Rasteiro (2015), num estudo realizado pela empresa Zanettini Arqueologia para a Usina Guarani na região de Olímpia/SP. Ao fazerem uma nova análise das peças que foram retiradas do sítio Maranata, "averiguou-se que a coleção é composta por vasilhas de contorno piriforme, vasilhas semiesféricas de contorno simples, e uma pequena vasilha geminada". No entanto, duas dessas vasilhas piriformes apresentaram "a decoração pintada vermelha composta por linhas e pontos aplicados com os dedos diretamente em superfície", e isso "remeteria a um possível contexto de fluxo de informações entre esses grupos Jê e Tupi” (RASTEIRO:2015:66).

Essas observações ficam claras nas pesquisas de Pereira Jr. sobre os dados que ele pôde coletar em estudos realizados na região de Franca/SP, quando assinala que,

Devemos fazer notar, entretanto, que em dados casos, entre restos abundantes dessa cerâmica preciosa tida como de origem tupi-guarani, ocorre um ou outro fragmento de material que, pela sua apresentação sugere origem diferente, enquanto que em locais ocorre o contrário, ou seja, o encontro dessa cerâmica melhor entre os restos de outra mais grosseira acentuadamente diversa. (PEREIRA JR:1957:134; apud RASTEIRO:2015:66)

O mesmo ocorre no relato exposto acima do memorialista Hildebrando Pontes, do encontro de uma urna na cidade de Araxá, semelhante as descritas entre os Tupinambá, com características da Tradição Tupiguarani, isto é, cerâmica de decoração e ligada a enterramentos primários, em área de ocupação histórica de grupos Jê. E mais, pois os relatos de Hildebrando mostram não apenas os contatos intertribais, como também interétnicos, mostrando como no período colonial os agentes históricos foram diversos e as trocas transculturais.

A variabilidade material encontrada nesses sítios nos indica, pois, fluxos de pessoas, saberes, bens materiais e simbólicos que circulavam entre os diferentes povos, tanto no período pré-colonial como colonial, na região dos atuais Triângulo Mineiro, norte de São Paulo e sul de Goiás. Por isso, as evidências materiais dessa variabilidade podem nos indicar 
não apenas um fluxo constante de ocupações e reocupações humanas nessa região, como a clara situação de contato entre diferentes alteridades. Dados arqueológicos, históricos e etnológicos suficientes parecem fatalmente apontar para o fato dos povos indígenas no Brasil não terem sido fechados ou imóveis, relegados a ocupação de apenas uma área como se ela fosse um isolado puro das tradições. Pelo contrário, esses povos sempre estiveram em movimento, ocupando diferentes espaços, as vezes até concomitantemente e, portanto, suas ocupações não formavam fronteiras fechadas ou barreiras, mas se sobrepunham e eram fluidas.

Um exemplo etnográfico talvez possa ser situado no caso dos povos Tupi ${ }^{3}$, que não viviam apenas no litoral brasileiro, mas ocupavam também trechos ao longo do curso do Amazonas, interrompidos por outros trechos ocupados por falantes de línguas Aruak, Karib, Tukano e outros grupos menores (BROCHADO:1989:66). As comunidades falantes Tupi se estendiam, de forma interrompida, desde a desembocadura do Amazonas, até o Atlântico, inclusive ocupando terras baixas "rodeando os planaltos brasileiros habitados por falantes de línguas do Tronco Macro-Jê” (BROCHADO:1989:66-67). Se considerarmos esses dados, é fácil supor que os grupos Tupi sempre estiveram em constantes contatos com grupos Aruak, Karib, Tucano, Jê etc.; e como sempre as fronteiras são porosas e sobrepostas, o pressuposto é o da constante transmissão, circulação e predação de elementos culturais, pessoas, conhecimentos entre esses diferentes povos.

Devemos ter por certo que, seja no período histórico ou pré-colonial, os grupos humanos sempre se constituíram pelos inúmeros contatos. No presente, como no passado, uma série de rupturas e continuidades se deram: agenciamentos, alianças, guerras, vivências, predações, ressignificações, de modo que as populações estiveram constantemente em processo de produção de suas vidas, passando por contínuos momentos de transformação. Neste caso, o que parece importar não é a imagem cristalizada que se atribui à essas populações indígenas e à sua expressão material, como querem as tradições arqueológicas, mas sim o processo, a vida, o devir, o acontecimento do processo daquele material, que não tem um fim.

\footnotetext{
${ }^{3}$ A utilização das nomenclaturas Tupi e Tupi-Guarani neste trabalho "seguem as classificações propostas por Rodrigues (2002). De acordo com as mesmas, o uso da nomenclatura Tupi ou Proto Tupi faz referência ao Tronco Linguístico do qual o Tupi Guarani é apenas uma das famílias, com vários idiomas e povos falantes, entre os quais os mais conhecidos são os Guarani (Mbya, Nhandeva e Kaiowá)" (MANO:2009:112).
} 


\section{Nanduty}

Em face das contribuições de Tim Ingold (2015) para a Arqueologia, em específico, e para as Ciências Humanas, em geral, devemos compreender que ser não é estar em um lugar, mas estar ao longo de caminhos. Portanto, devemos ser capazes de nos utilizarmos das Tradições Arqueológicas não enquanto encerramento, mas enquanto movimento de abertura, enquanto ponto de partida de um processo de expansão do conhecimento que nos leva a dinâmica das relações humanas. Não pensando somente o artefato material, mas a vida. Segundo Ingold, "se nossa preocupação é habitar este mundo ou estudá-lo, (...) a nossa tarefa não é fazer o balanço de seu conteúdo, mas seguir o que está acontecendo, rastreando as múltiplas trilhas do devir, aonde quer que elas conduzam." (INGOLD:2015:47). Para traçar essas trilhas, não devemos nos ater apenas ao material, mas ir ao encontro dos itinerários e dinâmicas humanas que permitiram a produção e significação dos elementos materiais. Para isso, a Arqueologia deve ser conduzida no diálogo com a História e a Etnologia para englobar as teias de significados e as redes de identidades e alteridades dos povos que estiveram em contato.

\section{AS TRILHAS DO DEVIR: DA HISTÓRIA À CULTURA}

Os relatos descritivos e os documentos históricos produzidos durante o período colonial posicionaram os indígenas em relação aos agentes coloniais, criando tensões "entre as políticas que buscavam ou assimilar ou excluir as populações indígenas" e "acirrava-se a disputa entre aqueles que defendiam a "civilização e catequese" e aqueles "parciais ao afastamento ou mesmo extermínio das populações nativas.” (MONTEIRO:2001:29). Daí nasceram as respectivas visões da aculturação e do extermínio dos povos indígenas. Fadados ao movimento de uma força primeira que lhe é exterior, a história indígena foi compreendida como linear ou, às vezes no simétrico oposto da aculturação, como a resistência de uma história cíclica.

De certa forma, essas visões da história, como os modelos das tradições arqueológicas, resultam da "tendência seguida por sucessivas gerações de historiadores e antropólogos que 


\section{Nanduty}

buscaram isolar, essencializar e congelar as populações indígenas em etnias fixas. [...]" (MONTEIRO:2001:24). É com base nessa tendência que a História e a Etnologia construíram modelos indígenas com base em binarismos fixos, tais como: Tupi/Tapuia; mansos/selvagens; aliados/inimigos; primitivos/civilizados; centrípetos/centrífugos; espaciais/temporais etc. Ao invés de contribuir para uma história dos índios, esses modelos tornaram essa mesma história opaca, ofuscada, desleal. Mas se aí existem, como pensa Carlo Ginzburg (1989:177) "zonas privilegiadas - sinais, indícios - que permitem decifrá-la”, sua construção deve ser procurada numa história fora de essencialismos, binarismos e imagens folclóricas; ao contrário, ela deve ser uma história na qual os indígenas "apareçam como sujeitos históricos que agem politicamente a partir de signos e interesses próprios, continuamente transformados nas dinâmicas de suas relações sociais". (ALMEIDA:2011:33; apud FERREIRA FILHO: 2015:12).

Em face dessas advertências, as trilhas da história indígena no Triângulo Mineiro, norte de São Paulo e sul de Goiás só podem ser pensadas como resultado dos contatos entre uma série de agentes, estratégias e processos dinâmicos que incluíram guerras, alianças, trocas, consumos e possibilitaram a circulação de pessoas, saberes e bens que resultaram, então, na produção de vestígios materiais com características híbridas e sítios arqueológicos complexos. Segundo Robert Mori (2015: 13) o Triângulo Mineiro e parte do Alto Paranaíba era conhecido até meados do século XIX como "Sertão da Farinha Podre", quando as bandeiras paulistas avançavam em busca de riquezas. Ao longo da história outros nomes foram dados à região, como "Sertão do Gentio Cayapó", , sendo a região do Triângulo Mineiro e parte do Alto Paranaíba, na época, correspondentes ao sul da Capitania de Goiás.

No período colonial, essa região foi área associada aos Jê Meridionais, que parecem ter ocupado um extenso território desde o norte de São Paulo até as imediações do Distrito Federal, e no sentido leste - oeste, do atual Triângulo Mineiro até ao norte do Mato Grosso do Sul. (MANO: 2015:521). Entre esses grupos deviam existir hordas de "Cayapó" meridionais, dos quais os Panará são remanescentes (GIRALDIN:1997), mas é possível assinalar a existência de outros povos indígenas dos Jê Meridionais e também não Jês que estavam nos limites desse território, tais como os Payaguá, os Xakriabá, os Xavante, os Avá-Canoeiro e os

\footnotetext{
${ }^{4}$ A região recebeu diferentes denominações, como "Sertão do Rio das Velhas", "Sertão do Novo Sul", "Sertão dos Novos Descobertos do Paranaíba" e, por fim, "Sertão da Farinha Podre" (PONTES:1978, apud MORI: 2015: 13)
} 


\section{Nanduty

Bororo. (GIRALDIN, 1997:57). Com base nisso, Robert Mori (2015:25) propõe que a existência de outras etnias indígenas na mesma área de ocupação dos Jê Meridionais "Cayapó" pode ter favorecido que outros grupos indígenas que também tenham empreendido ataques, conflitos e mortes fossem associados à generalização do termo "gentio Cayapó".

O contato dos Jê Meridionais com os não-índios teve início já nas primeiras décadas do século XVII. Segundo Vasconcelos (2013), a partir de documentos históricos, têm-se evidências de que por um período esse contato foi pacífico e de que as aldeias indígenas serviram de ponto de parada e reabastecimento das bandeiras paulistas que adentravam o Brasil Central. Não tardou, porém, para que essa realidade começasse a mudar e as guerras passassem a ser impetradas por ambos os lados. Do lado não índio, a expansão da economia mineradora assinalava o motivo fundamental do bandeirismo: a necessidade crônica de mãode-obra indígena para a manutenção da agricultura paulista. (MONTEIRO:1994:57) e a limpeza ou desinfestação dos caminhos que levavam às minas. Do lado indígena, e como já foi proposto (MANO: 2011:2012), a guerra parece ter sido parte do regime relacional e simbólico de relação desses grupos Jê com algumas de suas alteridades, num claro processo de predação exterior para produção interior. Do encontro dessas duas lógicas decorreu uma das mais longas e sangrentas guerras entre índios e não índios na América colonial portuguesa.

Com grande população, os Jê Meridionais foram vistos no XVIII e XIX como um obstáculo ao avanço da "civilização", ligada a descoberta de minas auríferas no início do século XVIII e ao grande movimento de não índios para essa área. Não fossem as já existentes guerras intertribais empreendidas entre os Kayapó, Xerente, Xavante, os embates mais conhecidos a partir do período colonial foram entre os Jê Meridionais e os não-índios que avançavam cada vez mais sobre o território desses grupos. O local de maior contato e conflito foi a estrada conhecida como "Caminho de Goiás", que cortava a atual região do Triângulo Mineiro, já que era um local estratégico para o escoamento de ouro para São Paulo e Rio de Janeiro. Nesse momento, a política da Colônia em relação aos índios da região foi voltada para o extermínio e a desinfestação. Devido aos inúmeros conflitos, em 1742, Dom Luiz de Mascarenhas dava instruções claras para a conquista, escravização e extermínio dos Kayapó. (D.I.: vol 22:185).

Ainda importante apontar que pouco mais tarde, com o declínio da economia mineradora, "tais regiões sofreram um enorme esvaziamento populacional e aqueles que ali 


\section{Nanduty}

permaneceram promoveram a ascensão da economia agropecuária e continuaram a expulsar, “domesticar” ou matar" os índios (GIRALDIN:1997; ATAÍDES:1998; KARASCH:1998; apud VASCONCELOS:2013:35).

Houve diferentes formas de combater o "gentio Cayapó". A primeira "solução" encontrada, vinda da Câmara de São Paulo, "foi a proposta de criação de duas campanhas pagas e lideradas por um comandante". (MORI:2015:32) que pouco efeito surtiu. Nesse contexto o Conde de Sarzedas e Dom Luís Mascarenhas, autorizam qualquer morador da região a realizar combates contra esses grupos e "dar por captivos todos os que apanharem" (MASCARENHAS: 1740; apud MORI: 2015:33). A solução seguinte foi a construção de aldeamentos na região do atual Triângulo Mineiro, entre o rio Grande e Paranaíba, para receber índios de diferentes etnias (Bororo, Xakriabá, Pareci, Javaé, Kurumaré), administrados por Antônio Pires de Campos e autorizados a fazer guerra ofensiva ao "gentio Cayapó". Entre 1742 e 1775 foram criados diferentes aldeamentos na região, sendo os mais conhecidos o de Rio das Pedras, primeiro aldeamento de Goiás construído ainda sob a jurisdição da Capitania de São Paulo; e Santa Ana do Rio das Velhas, criado em 1750, sendo ambos entre os Rios Grande e Paranaíba. Esses aldeamentos tinham o propósito de "serem locais para defesa do Caminho dos Goiases e demais arraiais da Capitania de Goiás contra os ataques dos Kayapó do Sul." (MORI:2015:76). No Rio das Pedras "foram deslocados os Paresí e os Bororo, oriundos do Mato Grosso, totalizando em setembro de 1748, trezentos índios entre adultos e crianças [...]” (Idem:2015:79). Posteriormente, durante o período do Diretório, grupos "Cayapó" de Camapuan e do rio Grande foram atraídos para o aldeamento de Maria I em 1780, criado exclusivamente para receber esses indígenas, chegando a reunir por volta de 600 guerreiros e suas famílias, estimando-se aproximadamente 3.600 índios. (VASCONCELOS:2013:35).

Apesar de todas essas tentativas, a resistência desses grupos foi uma constante e seus ataques perpetuaram-se mesmo após o aldeamento em Maria I. Esse fato deve ser explicado não apenas pelo desejo de sobrevivência, mas também ao desejo de predar o outro ou, como dissemos acima, porque a guerra foi parte do regime relacional e simbólico desses grupos com a alteridade (MANO:2011;2012) que implicou, entre outros, no saque de bens simbólicos e materiais de seus outros para alimentar a sua própria cultura. E o modo mais eficaz de se predar a alteridade para "Gentio Cayapó" foi a guerra. Seu poderio bélico foi descrito em 
diversas ocasiões, e desde a primeira descrição desses grupos feita por Antônio Pires de Campos:

\begin{abstract}
As armas de que usam são arcos muito grandes e flechas muito compridas e grossas, e também usam muito de garrotes, que são de páu de quatro ou cinco palmos com uma grande cabeça bem feita, e tirada, com os quais fazem um tiro em grande distância, e tão certo que nunca erram a cabeça; e é a arma de que mais se fiam, e se prezam muito dela. (CAMPOS:1976:182)
\end{abstract}

Dentre as armas, esse sertanista indica a borduna, instrumento de esfacelamento do crânio do inimigo, utilizado por outros grupos indígenas, inclusive pelos Tupi, que dão o nome ao instrumento de mesmo uso de Ibirapema, utilizado nos rituais antropofágicos na morte do prisioneiro. O uso dessas bordunas pelos Jê Meridionais lhes deu a denominação de Bilreiros ${ }^{5}$ na documentação histórica. (CHAIM:1983; ATAÍDES:1998; MONTEIRO:1994).

De acordo com Giraldin (2001) e Mano (2011) a maior parte dos relatos de ataques dos Jê Meridionais apontavam um mesmo padrão: "matavam todos, pilhavam bens que podiam carregar e queimavam as casas." (GIRALDIN:2001:63). Por essa estrutura de ataques contra os não índios, a guerra servia para realizar a predação das partes objetiváveis do outro, do "inimigo", numa destruição de corpos "inimigo" e apropriação de seus bens para a produção de corpos em seu interior. Por isso, a destruição do exterior implica na construção de pessoas no interior; ocorrendo, assim, como já propôs Carlos Fausto (2001) para os Tupi, na predação canibal, o consumo produtivo, quando da incorporação do "outro" para a construção do "nós". Por isso, assim como para os grupos Tupi existe abertura ou uma força centrífuga, os povos Jê não são fechados ou centrípetos, mas estão constantemente se movimento entre os dois pólos, pois ora se abrem para o exterior, predando o outro, o inimigo, tomando-lhe partes; ora se fecham, ressignificando aquilo que foi tomado como ser constitutivo da sua própria cultura.

Se esses pressupostos estiverem corretos, as sociedades indígenas vivem num processo histórico contínuo que opera um misto de permanência e mudança, estrutura e evento. Afinal, a abertura para a alteridade e a apropriação de seus bens, por mais que coloque em prática uma estrutura original, simultaneamente carrega eventos com novas significações. Assim, tal

\footnotetext{
5 A denominação Bilreiros se deve a semelhanças das bordunas dos Kayapó Meridionais com o Bilros, instrumentos utilizados para a confecção de rendas.
} 


\title{
Nanduty
}

como pensa Marshall Sahlins (1987), a história é culturalmente ordenada, tanto quanto a cultura é historicamente ordenada.

\begin{abstract}
A História é ordenada culturalmente de diferentes modos nas diversas sociedades, [...] esquemas culturais são ordenados historicamente porque, em maior ou menor grau, os significados são reavaliados quando realizados na prática. [...] a cultura é historicamente reproduzida na ação. [...] as circunstâncias contingentes da ação não se conformam necessariamente aos significados que lhe são atribuídos [...]. É nestes termos que a cultura é alterada historicamente na ação. (SAHLINS:1987:7)
\end{abstract}

Marshall Sahlins compreende o misto entre estrutura e evento, ou seja, a junção entre estrutura e práxis histórica, pois os indivíduos agem e movimentam a história de acordo com seus interesses, signos e circunstâncias. E mesmo que a ação seja realizada a partir de pressupostos culturais pré-existentes, a práxis, a ação humana consciente, será capaz de movimentar essa estrutura, redefinindo-a e atualizando-a constantemente, já que a transformação de uma cultura é também modo de sua reprodução. No caso dos grupos Jê meridionais - "Cayapó" pode-se afirmar que:

Se, no confronto entre lógicas culturais distintas, o que os estudos das relações de contato ilustram particularmente bem, um primeiro momento é o da reprodução da estrutura, ou seja, a interpretação do acontecimento segundo as categorias culturais pré-existentes, a guerra para os Kayapó parece ter servido a uma espécie de ordenação simbólica da história. (MANO: 2012:134)

Podemos perceber tanto pela mitologia, quanto pela história do contato do século XVIII que desde os tempos míticos até o presente, as inovações nos modos de vida dos Jê Meridionais são, em grande parte, fruto de aquisições feitas em terras alheias, por meio da predação de seus outros. Percebemos essa predação ontológica a partir do mito do gavião-real gigante, que permeia a cosmologia dos Jê Meridionais. Nesse mito, são apresentadas as personagens dos irmãos Ngôkon-Kry e Kukryt-Twiri que tiveram papel importante na formação da nação desse povo. O gavião foi tido como culpado pela morte de sua avó e tiveram que travar uma luta contra esse grande gavião procurando vingança. Um dos irmãos,

Ngôkon-Kry foi lá fora, flechou-o e furou-o com sua lança. Depois bateu na cabeça dele com sua borduna. [...] arrancou uma pena branca do gavião-real e colocou-a na cabeça. Pintou-se de preto. [...] Os rapazes (mebengàdjyre) arrancaram suas penas e jogaram-nas para cima dizendo: "Virem aves!" Transformando-se em mutum. É por isso que, hoje em dia, há espécies diferentes de aves. (LEA:2012:34) 


\section{Nanduty}

Nesse mito percebemos a tomada de bens e riquezas materiais e imateriais. Adquiriram os adornos plumários, mas não só, através dessa batalha conquistaram a criação de várias aves, assim como adquiriram a glória, o prestígio. Quando os Jê Meridionais entram em contato com os não-índios a partir do século XVIII, da mesma forma que predaram o "outro" no tempo mítico, eles predam esses não-índios, pilhando objetos, adornos, e bens simbólicos.

Desse ponto de vista, os não índios que se interpuseram nos caminhos de ocupação e perambulação dos Kayapó, forneceram as chances históricas para esses indígenas atualizarem as façanhas heroicas de seus heróis míticos fundadores. As estruturas e o conteúdo das relações mitológicas com a alteridade se repetiram na história. Como no mito foram corajosos na luta contra a ave predadora de gente, na história foram bravos e ferozes contra os não índios. Como no mito mataram e destruíram o inimigo (matam e cortam o gavião), na história mataram os não índios e destruíram tudo que encontraram. Como no mito se apropriaram de bens materiais e simbólicos da alteridade (do gavião, da onça, dos peixes), na história se apropriaram de bens materiais móveis e simbólicos em suas expedições e guerras de pilhagem. (MANO:2012:147)

Segundo César Gordon,

Seja como for, é possível dizer que no caso mebêngôkre, diferentemente do caso tupi, a morte de um inimigo tem menor produtividade que aquilo que fenomenologicamente aparece-nos como um 'roubo'. O signo da apropriação mebêngôkre não é o canibalismo - sabemos que eles não são canibais, não comem o inimigo -, o signo é uma espécie de captura. (GORDON:2006:99)

Assim, temos que se "trata menos de capturar o corpo (ou partes do corpo) e o espírito do inimigo do que sua cultura (imaterial e material), ou sua riqueza, sua beleza, enfim, suas propriedades não imediatamente corpóreas [...]" (GORDON:2006:97). Portanto, os Jê Meridionais "têm como motivação da guerra predar ontologicamente a cultura do outro e adquirir objetos desta outra cultura, sendo, portanto, a guerra uma forma de conservação do contato com o mundo exterior." (JUNQUEIRA:2017:20). Essa predação da alteridade nos confere certa possibilidade de afirmar que a cruz de ouro encontrada junto aos ossos dentro de uma urna mortuária, nos relatos de Hildebrando Pontes expostos acima, se deve a essa predação, à tomada de bens objetiváveis, como poderia ter sido a cruz, que incorporada e ressignificada, passou a constituir parte do universo material e simbólico daquele indivíduo enterrado na urna. 
Não obstante o contato com os não-índios, pelo seu modo de ser e predar, os Jê meridionais também estabeleceram redes de contato com diferentes outros. Segundo Marcel Mano (2015), a área que compreende o Triangulo Mineiro, oeste de Minas e sul de Goiás foi palco de uma complexa rede de contatos entre diferentes agentes históricos. Desde a década de 1730 ,

Uma itinerância da sociedade colonial em direção aos sertões colocou em movimento sujeitos de diferentes estamentos sociais: homens livres pobres, mestiços, negros forros, foragidos, garimpeiros, roceiros, índios escravos, agentes do poder colonial etc. (Amantino, 2001; Barbosa, 1971; Souza, 2004) se locomoviam desde o oeste de Minas cruzando o alto rio São Francisco e a Serra da Canastra em direção ao atual Triângulo Mineiro e sul de Goiás. Mas ao se porem em marcha, esses diferentes sujeitos entraram ainda em contato com diferentes outros. (MANO:2015:512)

Os Jê Meridionais tiveram sua imagem construída pelos não-índios, ou por "alegorias da colonização", como sendo aqueles "bravios", "selvagens", a que "tudo levam de traição e rapina" (CAMPOS:1976:182). Mas ao contrário do que se poderia supor, por mais que a guerra fosse constitutiva do próprio modo de ser desses povos, eles fizeram alianças e movimentaram seus interesses de acordo com os diferentes agentes históricos que entraram em contato. À exemplo da aliança realizada com os negros fugidos, quando houveram "trocas mútuas, ações conjuntas e alianças entre os "gentios" e os "calhambolas"6 (MANO:2015: 524).

Nesse sentido, índios e negros mantiveram intricadas relações no século XVIII, e cabe ressaltar que "a continuidade e existência dos quilombos por longos períodos estão intimamente relacionadas com as ajudas de agentes externos e internos" (GUIMARÃES:1996; AMANTINO:2001; RAMOS:1996 apud ALVES: 2017:47), entre os quais os grupos indígenas.

Imergimos pelos indícios históricos, e debruçamo-nos, principalmente, no contato interétnico entre negros aquilombados do Ambrósio e índios Jê meridionais, em especial, os Kayapó. De um lado constatamos a existência de uma sociedade guerreira

\footnotetext{
6 “Autores como (Amantino, 2001; Lourenço, 2005; Martins, 2008) já chamaram a atenção para as influências indígenas nos modos de adaptação das populações dos quilombos.” (MANO:2015)
} 
que via na predação de outrem uma espécie de ontologia social e identitária. O que poderia, a partir da bravura como elemento de mediação, justificar suas alianças com outros grupos, como por exemplo, os calhambolas. (ALVES:2017:159)

Ao que tudo indica, a inusitada aliança pode ter se realizado devido aos semelhantes modos de tratamento que a Coroa Portuguesa mantinha com os índios e negros fugidos, de intenso combate e violências de todas as formas. Por isso, contatos, trocas, agências, dinâmicas, guerras e todas as possíveis formas de relações entre diferentes agentes numa situação de contato nos permitem pensar a construção e (re)construção continua de significações e elementos matérias, de redes de identidades e alteridades dos Jê Meridionais com seus diferentes outros no período colonial, o que torna possível compreender a existências de elementos matérias de grupos não Jê e de não-índios nos registros arqueológicos da região ocupada por esses grupos.

\section{A CONSTRUÇÃO DA IDENTIDADE ÉTNICA NO ENTRE-LUGAR}

A crença de que a cultura é estática, essencializada, imutável, foi dada enquanto mito e enquanto farsa. Enquanto mito pois ainda é presente nas leituras de mundo de senso comum que o indígena, para ser indígena, deve ser puro, aquele relegado a seu passado, vivendo em matas, desprovidos de roupas, com a mesma cosmologia de sempre e sem se utilizar qualquer máquina ou falar a língua portuguesa. Enquanto farsa porque essa crença não se constitui ao léu, mas é revestida de propósitos políticos que buscam deslegitimar os povos indígenas enquanto tais, destituí-los de suas identidades, de suas pertenças, para que assim se lhes possa sacar a terra e todos os seus direitos.

Na contramão desta crença tão bem dissimulada por agentes do poder, se encontra a acertada constatação de que a cultura é processo dinâmico, é movimento, é transformação. Manuela Carneiro da Cunha em seus extensos estudos sobre a etnicidade afirma categoricamente que "a cultura não é algo dado, posto, algo dilapidável também, mas sim algo constantemente reinventado, recomposto, investido de novos significados; e é preciso perceber a dinâmica, a produção cultural.” (CARNEIRO DA CUNHA:2009:239). Assim temos por certo de que o próprio existir no mundo, e o existir em relação à alteridade, nos 


\section{Nanduty

tornam seres em constante processo de mutação. Nenhum povo é fixo, mas se movimenta, encontrando em todos os lugares aonde chega os seus contrários, permitindo com que o ato de afirmar e o de incorporar se confunda num misto de permanência e mudança, ou como afirma Sahlins (1987) aludido acima, mostre que a transformação da cultura também é um modo de sua reprodução.

Tendo em vista a cultura como processo continuamente reinventado, poderíamos conceber a identidade da mesma forma. Isso significa pensar, como Sahlins (1987), que em processos de encontro com suas alteridades, num primeiro momento o grupo aguça e exerce os elementos e representações que lhes são particulares, seja para a seu posicionamento político ou de reconhecimento de uma situação de contraste; e num segundo momento, o movimento é de abertura, de contato, de aquisição de elementos dessas alteridades, e de ressignificação e (re)construção de sua cultura e identidade. Portanto, cultura e identidade são construções simbólicas e históricas, e enquanto tais mutantes, pois dispostas às intrincadas redes de significação histórica que os homens produzem e da qual são parte.

Do ponto de vista concreto, a identidade só poderia se constituir e (re)constituir de forma relacional, se encontrando, se formando e reformando em seus pontos de encontros com as alteridades. No caso aqui em questão, o encontro dos grupos Jê meridionais com suas diversas alteridades (índios, não índios, negros, mestiços etc.) durante o período colonial, criou uma série de variáveis possíveis cujo desenho já se definiu como mandala (MANO: 2015b), porque composta de diferentes pontos de cruzamentos e intersecções, num sistema aberto e cambiável de relações que formam encontros variáveis. Nestes pontos de encontros, e considerando a identidade enquanto relacional, Friedrik Barth foi um dos precursores em direcionar os estudos sobre a identidade não mais para dentro dos grupos étnicos, mas para a fronteira, baseando-se na premissa de que toda cultura é descontínua, isto é, dinâmica. Isto indica que - contrariando a visão equivocada de que é a distância e o isolamento de um grupo social que mantém a diversidade cultural - "as fronteiras étnicas permanecem apesar do fluxo de pessoas que as atravessam.” (BARTH:1997:26). As categorias étnicas são mantidas apesar e em detrimento dos contatos estabelecidos, em movimentos de exclusão e incorporação, em transformações nas formas de pertencimento ao longo dos fluxos da história, cujos caminhos, desde a origem, são sempre diversificados. 


\section{Nanduty}

A criação, manutenção e transformação das fronteiras sociais é dada nos constantes contatos entre grupos e culturas. $\mathrm{O}$ que mantém os grupos étnicos é a evidência dos traços marcantes de sua cultura em contraste com a cultura do outro, mas isso não quer dizer que não haja troca, interação e incorporação a partir dos contatos. Nas fronteiras, se por um lado os grupos se certificam da garantia de certas persistências, por outro permitem e são parte da incorporação de códigos e valores externos a serem ressignificados.

Nesse sentido, a continuidade de um grupo é mantida na medida em que as pessoas, dentro de um repertório cultural disponível, acionam traços e elementos materiais e simbólicos para se autodesignarem enquanto pertencentes a tal e qual grupo. Ao fazerem isso, delimitam suas fronteiras de diferenciação, não obstante ao fato de, nessas mesmas condições, estabelecerem contatos, experiências e aquisições para renovação de seu repertório cultural. Segundo Paula Monteiro, isto nos permite compreender que a identidade não é dada em termos de uma natureza essencial a cada grupo social, mas é na verdade um "jogo simbólico no qual a eficácia depende do manejo competente de elementos culturais." (MONTERO:1997:63).

No mesmo caminho, Manuela Carneiro da Cunha (2009), ao retomar Weber, já indicava que as comunidades étnicas são formas de organização política muito eficientes para resistência e conquista de espaços. Além disso, na contramão dos conceitos de sincretismo e aculturação muito comuns na etnologia brasileira, o pressuposto é de que a cultura se atualiza em situações de contato.

A cultura original de um grupo étnico, na diáspora ou em situações de intenso contato, não se perde ou se funde simplesmente, mas adquire uma nova função, essencial e que se acresce às outras, enquanto se torna cultura de contraste [...]. A cultura tende ao mesmo tempo a acentuar, tornando-se mais visível, e a se simplificar e enrijecer, reduzindo-se a um número menor de traços que se tornam diacríticos. (CARNEIRO DA CUNHA:2009:237)

Tendo em vista essas constatações, e em face dos estudos acima mencionados, podemos certamente afirmar que a identidade dos Jê Meridionais jamais foi dada em termos de uma unidade rígida ou fixa, na medida em que, diante de diferentes agentes históricos, esses povos acionaram diferentes identidades, num jogo consciente de escolhas de diferentes formas e estratégias para se relacionarem com suas alteridades. 


\section{Nanduty

[...] várias diferenças ajudaram a construir e a reconstruir a identidade desses índios no período em foco. Ao invés de uma identidade única e inequívoca, parte dos dados sugere, ao contrário disso, a constituição de uma complexa e intricada rede de representações e ações desses índios sobre seus diferentes outros. (MANO:2015:524)

Home Bhabha (1998) em O local da cultura, nos indica que para entendermos essas complexas redes de representações e ações de diferentes agentes históricos, não devemos focar nossos pensamentos nos polos: passado e presente, interior e exterior, inclusão e exclusão, puro e impuro, tradição e modernidade, primitivo e civilizado, já que estes são modelos fixos e essencializados que não dão conta da realidade empírica. Ele indica o sujeito colonial como sendo aquele que se transforma a partir da incerteza que os contatos com os diferentes outros vão gerar. Nas palavras de Bhabha, o sujeito se torna "o menos que um duplo", pois ele não perde a sua cultura, mas também não deixa de absorver traços da cultura do outro, possuindo elementos culturais diversos em detrimento de seus contatos. É um ser, ou um povo, que é representação do outro através da mímica. Essa mímica revela este ser no "entre-lugar", na fronteira, onde se dão os contatos e as transformações e (re)construções das culturas e das identidades.

Em face desses argumentos, os achados arqueológicos das urnas mortuárias, tal qual descritas por Hildebrando Pontes (1930), quando colocados em relação à história indígena dos contatos na região, podem permitir a associação da presença de elementos culturais diferentes à noção de identidade como uma "fixidez deslizante" (BHABHA: 1998:111). Isto é, há algo de fixo que sempre existiu de forma mais consistente; mas por outro lado, cultura e identidade sofrem contínuos processos de construção e desconstrução a partir das possibilidades de deslizamento constantes em vias de aparecimento de um novo ser, que não deixa de ser o que é, muito embora seja um outro mais complexo.

Nesse sentido, temos por certo que devemos buscar as respostas para construção da identidade étnica nas figuras complexas híbridas, pois é justamente nos interstícios que nascem as experiências intersubjetivas que nos permitem uma melhor compreensão das complexas realidades existentes, como a dos Jê Meridionais, que ora mantiveram estratégias guerreiras de contato, ora comerciais, ora comerciais e guerreiras simultaneamente, ora de alianças, mas sempre auferindo do exterior bens materiais e simbólicos, historicamente manipulados a seu favor, comportando-se como sujeitos históricos conscientes de suas próprias historicidades. 
Por isso, um pensamento que não apreenda o movimento, a mutação e a transformação de todas as coisas não entende o múltiplo. Entre dois polos dicotômicos, coexistem milhares de possibilidades no caminho que leva de um a outro. Uma realidade que é múltipla, plural, transcultural, necessita de uma metodologia que seja capaz de captar esse múltiplo. Não é pela raiz da árvore do conhecimento que se melhor apreende o real, nem pelos polos binários. Segundo Deleuze e Guattari, em Mil Platôs, é pelo rizoma.

Num rizoma, há princípios de conexão que fazem com que qualquer ponto possa ser conectado a outro, e deve sê-lo. Sem raiz, começo ou fim, os pontos não se fixam em linhagens, hierarquias, cadeias biológicas, políticas, e econômicas, mas permeiam uma gama de significantes e significados ao entorno de um signo. O rizoma não possui raiz, não privilegia dimensões, mas age justamente no descentramento do conhecimento, não se fechando em si mesmo, mas se abrindo a expor as múltiplas dimensões da realidade, como aqui, no diálogo entre a Arqueologia, a História e a Etnologia.

Assim como na realidade, não há no rizoma unidade central, núcleo, raiz. Há a multiplicidade de dimensões, que crescem, recuam, se encontram, se desencontram, voltam a se conectar, e se desenvolvem sem regras às quais devem se submeter, numa conexão (quase) infinita de possibilidades. E "essas multiplicidades se definem pelo fora: pela linha abstrata, linha de fuga ou desterritorialização segundo a qual elas mudam de natureza ao se conectarem as outras”. (DELEUZE; GUATTARI:2011:25). A realidade é rizoma na medida em que seus múltiplos ramos se desencontram, se rompem, mas podem, a qualquer momento, se reencontrar, reconstituindo um sujeito, reestruturando um significado, ressignificando um signo.

Dessa forma poderemos ampliar o olhar na intenção de alcançar o múltiplo. Na Arqueologia, não se poderá mais olhar apenas para os objetos afim de classificá-los em tradições; mas olhar-se-á para as dinâmicas e processos intrínsecos àquele objeto que permitiram a sua construção e pensar o sujeito que o produziu, o momento em que se produziu e porque se produziu. Na História, poderemos enxergar processos rizomáticos, e não mais lineares, circulares, espiralados, pois os fluxos nos mostram que não há uma história universal do desenvolvimento humano, mas a história particular de inúmeras sociedades que estão em contato umas com as outras. Em Etnologia, poderemos problematizar os modelos etnológicos sincrônicos e fechados que reinaram nos estudos dos Jê, em favor do 


\section{Nanduty}

entendimento de que não há grupo humano que não tenha se constituído pela história e pela abertura, sendo, por si, um emaranhado profuso das vivências dos seus contatos. Por fim, esse olhar ampliado deverá ainda permitir compreender que a separação das áreas do saber não nos traz benefício, mas a cegueira, e que o enxergar depende muito mais da capacidade em articular diferentes saberes, do que de uma competência especializada.

\section{CONSIDERAÇÕES FINAIS}

O motivo inicial dessa reflexão foram os achados de urnas mortuárias no Triângulo Mineiro com elementos diagnósticos de culturas diferentes. Numa, o sepultamento indígena em urna convivia com o símbolo cristão da cruz; e noutra, o sepultamento indígena em urna apresentava elementos das tradições arqueológicas Aratu-Sapucaí e Tupiguarani. Ao invés de descartarmos esses elementos considerando-os intrusos, atitude própria de quem procura o purismo dos modelos, resolvemos alça-los à categoria de problemas. E problemas são bons para pensar.

Assim, desde esse motivo inicial a reflexão nos conduziu às questões de história e etnologia indígenas. Como uma dessas urnas é seguramente do período histórico, o contexto dos contatos de grupos dos Jê meridionais nos atuais norte de São Paulo, Triângulo Mineiro e sul de Goiás serviu para pensar uma complexa rede de identidades e alteridades como possível condicionante da imbricação de elementos diferentes em um mesmo artefato. Os contatos intertribais e interétnicos que se deram no período colonial entre diferentes agentes históricos permitiram, então, pensar que os sítios complexos são decorrentes de uma série de contatos que se estabeleceram ao longo da história. Daí, talvez, o exercício de classificar sítios e artefatos em tradições arqueológicas seja mesmo ingrato e enrijecedor, na medida que desconsidera as dinâmicas dos povos que produziram e usaram o artefato. Para além do fadado traços "intrusos", é preciso entender que elementos diferentes, tomados e apropriados de diferentes maneiras, são partes constitutivas dos grupos e de seus modos de ser, pensar e fazer, cuja chave do entendimento só pode estar nos complexos contextos históricos e culturais dos contatos. 
Se esse plano for adotado, a história indígena na região do Triângulo Mineiro, norte de São Paulo e sul de Goiás, não poderá mais ser vista como linear, seja no contexto de culturas de resistências ou das teorias de aculturação. No seu lugar deve brotar uma visão da história que, ao considerar os diferentes encontros e intersecções entre várias alteridades, possa ser melhor captada em termos de rizoma, isto é, sem raiz, mas repleta de platôs, dimensões, movimentos, encontros, rupturas, que são parte constitutiva da história desses grupos dos Jê na região em foco.

Por fim, o caminho traçado a partir do motivo inicial -as urnas-, agora contextualizado com as histórias dos contatos, desembocou em questões de etnicidade. Os modelos etnológicos fechados não permitiram até agora constatar os processos de abertura e de incorporação diferenciada da alteridade que podem provar como culturas, tradições e identidades não são fixas, mas relacionais e dispostas -por interesses e signos- a contínuos e dinâmicos processos de transformação histórica. Assim, a identidade dos Jê Meridionais, que não pode ser dada numa essência, sofreu processos de construção e reconstrução a partir dos encontros com as diferentes alteridades, numa eterna constituição do entre-lugar. É nesse espaço social que se produzem, se entrecruzam e se imbricam as diferenças culturais; e é a esse espaço que as urnas aqui tomadas parecem, muito claramente, pertencer.

\section{REFERÊNCIAS BIBLIOGRÁFICAS}

AFONSO, Marisa C.; MORAES, Camila A. 2005-2006. "O sítio Água Branca: interações culturais dos grupos ceramistas no norte do estado de São Paulo". Rev. do Museu de Arqueologia e Etnologia, São Paulo, nº15-16.

ALVES, M. A. 1992. "As estruturas arqueológicas do Alto Paranaíba e Triângulo Mineiro Minas Gerais”. Revista do Museu de Arqueologia e Etnologia, São Paulo, 2:27-47.

ALVES, M. A.; FAGUNDES, M. 2003. “Tecnotipologia da cerâmica pré-histórica do Projeto Quebra Anzol, Minas Gerais”. Anais do XII Congresso da Sociedade de Arqueologia Brasileira, São Paulo.

ALVES, Daniela Santos. 2017. Do Alto do Espia: gentios, calhambolas e vadios no sertão do Campo Grande - séc. XVIII. Dissertação de Mestrado em Ciências Humanas, Universidade Federal de Uberlândia. 
BAHBBA, Homi K. 1998. O local da Cultura. $2^{\mathrm{a}}$ ed. Tradução de Myrian Ávila; Eliana Lourenço de Lima Reis; Gláucia Renate Gonçalves. Belo Horizonte, Editora da UFMG. (Introdução: Locais da Cultura, p. 09-42)

BARTH, Fredrik. 2000. O Guru o iniciador: E outras variações antropológicas. Organização de Tomke Lask. Tradução de John Cunha Comerford. Rio de Janeiro, Editora Contra Capa.

BROCHADO, J. P. 1980. “A tradição cerâmica Tupiguarani na América do Sul”. Revista de Pesquisa Histórica, Pernambuco, no 03, p. 47-60.

1989. A expansão dos Tupi e da cerâmica da tradição policrômica amazônica. Dédalo: Revista de Arte e Arqueologia, São Paulo.

CAMPOS, Antonio Pires de. 1976. "Breve notícia do gentio bárbaro que há na derrota das minas de Cuiabá e seu recôncavo, na qual declara-se os reinos [...]". In: TAUNAY, Afonso d'E. (org). Relatos sertanistas. $2^{\mathrm{a}}$ ed, São Paulo, Editora Livraria Martins, p. 181-200.

CARNEIRO DA CUNHA, Manuela. 2009. Cultura com aspas e outros ensaios. $1^{\text {a }}$ ed. São Paulo, COSACNAIFY.

CARVALHO, Maria do Rosário de. 2011. "De índios misturados a índios regimados". In: CARVALHO, Maria do Rosário de; REESINK, Edwin; CAVIGNAC, Julie (orgs). Negros no mundo dos índios: imagens, reflexos, alteridades. Natal, Editora EDUFRN, p. 337-356.

DELEUZE, Guiles; GUATTARI, Félix. 2011. Mil Platôs: Capitalismo e Esquizofrenia, Vol. 1, São Paulo, Editora 34 Ltda.

FAGUNDES, Marcelo. 2015. "Histórico das pesquisas arqueológicas no Triângulo Mineiro: a história indígena pré-colonial”. In: FERREIRA FILHO; José Aurelino. Índios do Triângulo Mineiro: História, arqueologia, fontes e patrimônio, pesquisas e perspectivas. Uberlândia, Editora EDUFU.

FAUSTO, Carlos. 2001. Inimigos fiéis: história, guerra e xamanismo na Amazônia. $1^{\mathrm{a}}$ ed. São Paulo, Editora EDUSP.

FERREIRA FILHO, Aurelino. 2015. "Índios no Triângulo Mineiro: autoreconhecimento e direitos étnico-culturais". In: FERREIRA FILHO; José Aurelino. Índios do Triângulo Mineiro: História, arqueologia, fontes e patrimônio, pesquisas e perspectivas. Uberlândia, Editora EDUFU.

GINZBURG, C. 1989. Mitos, emblemas, sinais: morfologia e história. $2^{\mathrm{a}}$ ed. São Paulo, Editora Cia das Letras.

GIRALDIN, Odair. 2001. "Fazendo Guerra; Criando Imagens; Estabelecendo Identidades. A ocupação do centro-oeste e os conflitos com os Kayapó no século XVIII". Revista História Revista, nº6 (1), Goiânia, 55 - 74.

GORDON, César. 2006. Economia selvagem: ritual e mercadoria entre os índios XikrinMebêngôkre. São Paulo, Editora UNESP, Cap. 2, 10, conclusão. 
INGOLD, Tim. 2015. Estar Vivo: ensaios sobre movimento, conhecimento e descrição. Rio de Janeiro, Editora Vozes.

JUNQUEIRA, Gabriela G. 2017. O visível e o invisível nas relações de contato dos grupos Jê meridionais: uma análise da caça, guerra e dos rituais funerários como relações de predação e controle dos poderes latentes da alteridade. Dissertação de Mestrado em Ciências Humanas, Universidade Federal de Uberlândia.

LEA, Vanessa. 2012. Riquezas intangíveis de pessoas partíveis: os Mebêngôkre (Kayapó) do Brasil Central. São Paulo, Editora EDUSP. Cap. 8 e 9.

MANO, Marcel. 2006. Os campos de Araraquara: Um estudo de história indígena no interior paulista. Tese de doutorado, Universidade Estadual de Campinas, Instituto de Filosofia e Ciências Humanas.

.2009. "A cerâmica e os rituais funerários: Xamanismo, Antropofagia e Guerra entre os Tupi-Guarani”. Revista Interações - Cultura e Comunidade, Uberlândia, Editora Católica, v.4 n. 5 ; p. 111-128.

2011. "Contato, guerra e paz: problemas de tempo, mito e história". Revista Política e Trabalho, vol. 27, no 34, João Pessoa, p.193-211.

.2012. "Sobre as penas do gavião mítico: história e cultura entre os Kayapó”. Revista Tellus, ano 12, n. 22, Campo Grande, p. 133-154. 2015. "Índios e negros nos sertões das minas: contatos e identidades". Revista Varias Histórias, vol. 31, n. 56, Belo Horizonte, p. 511-546.

Itinerários e encontros culturais: índios e negros na história dos contatos dos Kayapó meridionais - séculos XVIII e XIX. Relatório final de pesquisa. CNPq, Processo: 477230/2012-1 -APQ, 2015b.

MATTOS, Izabel Missagia de. 2006. "O litígio dos Kayapó no Sertão da Farinha Podre (1847-1880)". Revista Dimensões, vol. 18, Vitória, p. 139-148.

MEDEIROS, João Cabral. 2007. Cultura material lítica e cerâmica das populações précoloniais dos sítios Inhazinha e Rodrigues Furtado, município de Perdizes, MG estudo de cadeias operatórias. Dissertação de Mestrado, Universidade de São Paulo.

MONTEIRO, John Manuel. 1994, Negros da terra - índios e bandeirantes nas origens de São Paulo. São Paulo, Editora Cia. das Letras.

2001. Tupis, Tapuias e os historiadores: Estudos de História Indígena e do Indigenismo. Campinas, Editora Unicamp.

MONTERO, Paula. 1997. "Globalização, identidade e diferença". Revista Novos Estudos Cebrap. No 49, São Paulo, p. 47-64.

MORI, Robert. 2015. Os aldeamentos indígenas no Caminho dos Goiases: guerra e etnogênese no sertão do Gentio Cayapó (Sertão da Farinha Podre) séculos XVIII e XIX. 2015. 232 f. Dissertação de Mestrado em Ciências Humanas, Universidade Federal de Uberlândia. 


\section{Nanduty}

ISSN:2317-8590

MUSEU DO ÍNDIO. 2018 Os Kayapó. Disponível In: http://prodocult.museudoindio.gov.br/index.php?option=com content\&view=article\&id=103 $\underline{\text { \&Itemid=262 }}$ (acessado em 29 de Novembro de 2018).

PONTES, Hildebrando. 1978. História de Uberaba e a Civilização no Brasil Central. $2^{\mathrm{a}}$ ed. Uberaba, Editora Academia de Letras do Triângulo Mineiro.

RASTEIRO, Renan Pezz. 2015. Arqueologia dos Jê da Bacia do Rio Grande: História Indígena no norte de São Paulo e no Triângulo Mineiro. Dissertação de mestrado em Arqueologia, Universidade de São Paulo.

ROBRAHN-GONZÁLEZ, E. M. 2000. "São Paulo: terra de fronteiras: a ocupação de grupos ceramistas pré-coloniais". IN: Anais do IX Congresso da Sociedade de Arqueologia. Rio de Janeiro.

SAHLINS, Marshall. 1987. Ilhas de história. Rio de Janeiro: Zahar Editor.

SCHMITZ, P.I et. al. 1982. "Arqueologia do Centro Sul de Goiás. Uma fronteira de horticultores indígenas no Centro do Brasil". Revista do Instituto Archietano de Pesquisas, n. 33, São Leopoldo, p. 49-102.

TURNER, Terence. 1992. "Os Mebengokre Kayapó: história e mudança social, de comunidades autônomas para a coexistência interétnica". In: CARNEIRO DA CUNHA, M. (org). História dos índios no Brasil, São Paulo, Editora Cida das Letras, p. 311-338.

VASCONCELOS, Eduardo Alves. 2013. Investigando a hipótese Cayapó do Sul-Panará. Tese de Doutorado, Universidade de Campinas. 